\title{
Transportation Research - Safety and Sustainability
}

\section{FOREWORD}

Most large cities in the world are already located in low and middle income countries and many more cities in these countries are expected to have populations of ten million or more in the next few decades. All these cities are faced with serious problems of inadequate mobility and access, vehicular pollution, road traffic crashes and crime on their streets. Increasing use of cars and motorized two-wheelers adds to these problems and this trend does not seem to abate anywhere. However, many recent reports suggest that improvements in public transport and promotion of non-motorized modes of transport can help substantially in alleviating some of these problems. Current evidence shows no success in reducing the use of personal motorized transport for long distance trips anywhere in the world and for urban trips in most locations. Most efforts to reduce environmental pollution due to road transport, therefore, focus on the control of exhaust emissions. This has produced some successes in reducing $\mathrm{CO}, \mathrm{SO}_{2}$ and $\mathrm{NO}_{\mathrm{X}}$ in a few locations, but not $\mathrm{CO}_{2}$ anywhere. As long as we use fossil fuels for combustion this problem is unlikely to be resolved unless we can shift modal shares towards non-motorized and public transport.

Most cities in the world are not successful in doing this. Even worse, transportation issues are so complex that there is little agreement internationally on what policies will help reduce vehicle-dependent travel without sacrificing social welfare. In this volume of $S \bar{a} d h n \bar{a}$ we have collected a set of articles that posit the problem and illustrate the complexity of analysis and expertise necessarily to deal with sustainable transport issues. All articles have been contributed by faculty members associated with the Transportation Research \& Injury Prevention Programme (TRIPP) at the Indian Institute of Technology Delhi, and international experts who have been collaborating with TRIPP.

Whenever sustainable transport issues are raised, discussions centre around vehicle emissions and pollution, and solutions on making vehicle engines more efficient and fuels cleaner. However, as Carlos Dora argues in this issue, the adverse health effects of motorized road transport go far beyond vehicle emissions. He reminds us that urban air pollution is estimated to cause around 800,000 deaths, road traffic crashes around 1,200,000, and reduction in physical activity about $1,900,000$ premature deaths annually. In addition, urban transport is a root cause of climate change, noise pollution (with adverse physiological effects), and busy streets have been linked to loss of community cohesion and pose limits to children's development. Dora argues that if we have to deal with all these problems, it is imperative that we go beyond narrowly focussed interventions of road and vehicle design only. Urban planners, transport specialists, medical and public health professionals, sociologists and engineers will have to work in coordination to understand the interlinked complexities involved. To make our cities liveable planners have to rethink city structures and transportation policies to make walking, bicycling and public transport safer and more convenient.

Hermann Knoflacher encapsulates a century of European experience and questions the very basis on which current transport policies are being made. He states that 'The core hypothesis of traditional urban and transport planning 'growth of mobility', 'travel time saving by 
increasing speed' and 'freedom of modal choice' are myths and do not exist in the real urban transport system. This is the reason why urban planning and transport planning based on traditional, non-scientific assumptions is creating continuously not only more transport problems, but also environmental, social and economic problems all over the world, where these principles are applied'. Knoflacher is convinced that car-centred planning and parking policies cannot deliver any solutions and wide, fast roads inside the city ultimately lead to more problems than congestion mitigation. If Knoflacher's diagnosis is correct then most of our city development plans are going in the wrong direction!

Tiwari et al in their article on traffic planning for non-homogenous traffic illustrate by a detailed analysis of Indian traffic that Knoflacher's complaint that traffic planners very often work on flimsy assumptions actually has some validity. Their analysis shows that traffic flow theories based on homogeneous traffic can lead us in the wrong direction in India. They postulate that when roads include vehicles of widely varying dimensions and operating characteristics, then drivers do not follow queuing behaviour but optimise space use and their logical behaviour gets termed as 'indiscipline' or 'chaotic'. When they analyse the actual behaviour of different vehicles on our highways they find that the actual space occupied by slower vehicles is actually much more than their size would suggest, and conclude that 'four lane divided highways with service lanes would be better than six-lane divided highways without service lanes... At present national policies in India promote the construction of 4-and 6-lane highways without much thought given to issues raised in this article.

The national Urban Transport Policy for India states that the 'Central government would promote investments in public transport as well as measures that make its use more attractive than in the past'. However, there is a great deal of confusion among policy makers whether public transport, especially bus transport, should be self-financing or subsidized to encourage use. Using a partial equilibrium model Sen et al make a case that 'If the reduction of congestion and other transport externalities is the prime motive of policymakers, then there is a case for subsidizing public transport'. Their article shows that these problems require reasonably complex analyses and the need for detailed data on travel patterns and costs. There are very few economists assessing the cost-effectiveness of urban investments in transport investments in India. There is no clear policy measure to ensure that if public transport needs some subsidy, where will this subsidy come from on a sustainable basis. Many city governments in India are investing in capital-intensive projects like metro rail but there is no serious econometric evaluation of these projects though many international researchers have raised questions about the social desirability of such projects. The goal of sustainable transport will remain unachievable unless sophisticated socio-economic studies are done to assess our choice of technologies.

For public transport to be made more popular, it is necessary that buses are made more comfortable. Kale et al use the latest modelling techniques to analyse air flow through nonair conditioned buses with open windows and come up with surprising results. They show that air does not necessarily enter form the front windows and exit form the back of the bus. Their modelling indicates that air can enter from the back and exit from the front while the bus is moving and when the velocities are low. This study is in its early stages but gives us a strong message that sophisticated technical analyses and experimental verification of bus shapes and vent locations would be necessary to improve air flow inside buses and make them more comfortable. It is even possible that air-conditioning could be made more efficient if optimal air circulation is ensured by use of such techniques. 
The issue contains six articles on transport safety. Matthijs Koornstra uses the product of time functions for the exponential decay of fatality risk per unit traffic volume and the S-shaped Gompertz function of traffic volume growth to predict future scenarios in road safety. He predicts that the global total of road traffic fatalities may begin to reduce only after 2035. This is a frightening thought, though he does offer a caveat that it may be possible to achieve this earlier if scientific principles of road safety get applied worldwide through a faster learning process. He does summarize for us what some of these principles are and shows that many of them are counter-intuitive. For example, 'One gets used to the average risk level in more or less the same way (but much slower) as for example in dark adaptation. Road users, therefore, are to a large extent indifferent with respect to a range of risks around the average road traffic risk'. This is why road and driver education programmes have been found to be ineffective or of little value the world over. Koornstra also warns us against placing too much faith on the capability of intelligent transport systems (ITS) in reducing death rates in the future. He lays stress on vehicle and road design features that help us in behaving safely and gives us a statistical guide to levels of traffic enforcement that are effective. He does believe that future improvements in vehicle design features might help reduce deaths by $40 \%$ in the long run in high income countries, but low income societies would have to pay more attention to the safety of pedestrians, bicyclists and motorcyclists by designing roads and habitations to reduce vehicle-pedestrian-bicycle conflict and control speeds. Koornstra gives guidelines for design of urban layouts that move in this direction. What should be of concern to us is that urban planners in India have little knowledge of this and none of the new urban developments are following these guidelines.

At present belted occupants of cars have approximately 50\% lower probability of getting killed in frontal crashes compared with unbelted occupants in $50 \mathrm{~km} / \mathrm{h}$ frontal crashes (Koornstra, this volume). Similarly, pedestrians and bicyclists have a $50 \%$ probability of getting killed at impact speeds of $40 \mathrm{~km} / \mathrm{h}$ (Koornstra, this volume). Therefore, future reductions in road traffic injuries also depend upon major improvements in crashworthiness of vehicles especially in pedestrian, bicycle and motorcycle crashes. Murray Mackay makes an important observation when he states that 'The scientific basis of those first generation crash performance standards was not well founded; many of the requirements were informed guesswork only. With the benefit of hindsight, quite extraordinarily few major mistakes were made, but what has become clear is that the subject is much more complex than the knowledge of the 1960s assumed.' Further, Mackay informs us that current safety standards are more protective of the healthy young male vehicle occupant and not as effective for the elderly and small female occupants and that vehicle designs are particularly deficient in protection of pedestrians and bicyclists. While a beginning has been made for introducing pedestrian impact standards for cars, none are on the anvil for bus and truck fronts. He makes a strong case for much better scientific investigations of car crashes and development of computer finite element models that mimic the human body more accurately than the dummies used today.

The last four articles by Chawla et al, Mukherjee et al and Pinnoji \& Mahajan illustrate how finite element and lumped parameter computer models are used to understand the basic mechanisms of impact dynamics involved in road safety research. Most current safety standards are based on human body and segment properties derived from impact tests done on human cadavers. In their article on finite element modelling of the human body, Mukerjee et al show that introduction of muscle forces changes the loading rates on structural elements of the body and hence injury criteria. They postulate that it is possible that the lower limbs 
might be able to withstand higher impact loads as the forces experienced by ligaments around the knee are lower if active muscle influences are accounted for. Such work is still in its primary stages internationally as experimental verification of the results is not a trivial matter. However, such findings are likely to have a major impact on the setting of vehicle-pedestrian impact standards over the next decade.

Motorized two-wheelers constitute the majority of vehicle populations in most countries of Asia including India. The fatality risk experienced by users of these vehicles is about twenty times greater than that by car occupants, but motorcycle safety has received much less attention internationally because it is not a major problem in high income countries. Airbags have become a standard safety item in high priced cars and an option in economy models but their application for motorcycle safety is unclear. Chawla et al investigate this by the application of a finite element computer model and conclude that airbag initiated injury is unlikely if motorcycles are equipped with airbags. Much more work needs to be done in this area as there are very few investigators working with full-scale motorcycle finite element models of different designs and sizes. All possible crash configurations will have to be investigated and results verified before we can be confident of introducing motorcycle airbags commercially.

The only safety equipment available for a motorized two-wheeler rider is a safety helmet. The current helmet safety standards are based on linear impact forces and accelerations experienced by a helmet with a rigid headform inside. Rotational accelerations are not accounted for though we do know that such movements influence head injury severity. Pinnoji \& Mahajan fine tune properties of the helmet shell and padding properties because they are able to estimate forces inside the head using a finite element model. It is only through investigations like this that the motorcycle helmet design can be optimized and standards changed. If this happens, it will result in the saving of thousands of lives and serious injuries in the near future.

The last paper in the volume by Mukherjee et al illustrates the use of modern modelling techniques applied to a problem specific to India and a few other Asian countries. They study the stability and impact characteristics of the three-wheeled scooter taxi (TST) commonly known as the Auto-riksha in India. A model of the TST manufactured by Bajaj Auto Ltd. has been used for this study. The results are quite surprising. Contrary to popular perceptions, the modelling results show that the vehicle is reasonably stable in turns as long as vehicle speeds are kept lower than $50 \mathrm{~km} / \mathrm{h}$. At present this is possible because such vehicles sold in India generally have an engine capacity less than $175 \mathrm{cc}$. This has important implications in that such vehicles should not be allowed to have powerful engines by policy and regulation. Impact modelling of the TST gives clear indications that cost-effective safety measures can be introduced by changing the properties of vehicle surfaces which are more likely to experience human body impacts.

Sustainable transport concerns involve many more technical and scientific issues than included in the eleven articles in this volume. However, the present collection of articles informs us that transportation policies that may result in reducing the adverse health impacts of road transport will require sophisticated inter-disciplinary research efforts. And, a great deal of cross-disciplinary communication. At present there are no educational or research institutions in India or other low and middle income countries that have given adequate importance to developing this expertise. The expertise that exists works mostly on individual initiative without enabling institutional frameworks and funding mechanisms. The purpose of publishing this collection of articles is to demonstrate that such work can only be done 
in an inter-disciplinary set-up involving a high level of scientific expertise. This will need policy decisions at the highest level in each country.

I would like to thank Professor Roddam Narasimha for encouraging us to produce this volume; our financial supporters for this work - Volvo Research and Educational Foundations, Ministry of Road Transport and Highways, Japan Automobile Research Institute (JARI); and, all the reviewers who helped in putting final shape to the contributions.

September 2007

DINESH MOHAN

Guest Editor 